\title{
Biology of pink stem borer, Sesamia inferens (Walker) on maize, Zea mays
}

\author{
Hemant Sharma*, Maha Singh Jaglan and S. S. Yadav \\ Department of Entomology, CCS Haryana Agricultural University, Hisar-125004 (Haryana), INDIA \\ *Corresponding author. E-mail: sharmahemant0608@gmail.com
}

Received: December 31, 2016; Revised received: April 2, 2017; Accepted: September 15, 2017

\begin{abstract}
Biology of pink stem borer, Sesamia inferens (Walker) (Lepidoptera: Noctuidae) was conducted during 2015-16 in laboratories of CCS Haryana Agricultural University, Regional Research Station, Karnal on HQPM 1 (hybrid) and HKI 1128 (inbred) for two generations at room temperature. Results on biology of S. inferens in the first generation revealed that incubation period varied from 10-14 days on HQPM 1 and 11-15 days on HKI 1128. The larval duration lasted for 21-37 days on HQPM 1 and 24-39 days on HKI 1128. The adult longevity of male and female ranged from 6-7 days and 7-8 days on HQPM 1 and 5-7 days and 6-7 days on HKI 1128, respectively. The total life span ranged from 63-72 days for female and 45-58 days for male on HQPM 1 and 65-74 days for female and 49-62 days for male on HKI 1128, respectively in the first generation. The total life span in second generation ranged 94-107 days for female and 83-96 days for male on HQPM 1 and 98-112 days for female and 86-101 days for male on HKI 1128. The biology of an insect pest is a condition precedent to find out its management strategies. The biology of $S$. inferens on maize has not yet been studied in north western part of the country. Having regards to the fact that no systematic work on this aspect has been carried out, studies were conducted on biology of this pest for developing efficient pest management strategies.
\end{abstract}

Keyword: Biology, Sesamia inferens, Maize, Zea mays

\section{INTRODUCTION}

Maize (Zea mays L.) is one of the most important cereal crops of the world, contributes to food security in most of the developing countries. It is cultivated over a wide range of agro climatic zones and the suitability of this crop to diverse environments is unmatched by any other crop. It is cultivated in more than 150 countries but the major maize producing countries are USA, China, Brazil, Mexico, France and India. In India, it is cultivated throughout the year in all states of the country for various purposes (grain, fodder, green cobs, sweet corn, baby corn and pop corn). Maize is important in human nutrition and also used as animal feed. It is cultivated throughout the year in different seasons (kharif, rabi and spring) in one or the other parts of the country. The demand of maize is increasing every day due to expansion of maize based industries. Maize is third most important cereal crop in India after rice and wheat. In India, it occupies an area of 8.78 million hectares and with a production of 21.76 million tones and average productivity of $2.48 \mathrm{t} / \mathrm{ha}$, whereas in Haryana this crop occupies an area of 11.00 thousand hectares having production of 30.00 thousand tones and average productivity of $2.73 \mathrm{t} / \mathrm{ha}$ (Anonymous, 2014). Average productivity of maize is very low in comparison to its potential. The gap between the productivity and the potential is very wide, there is tremendous scope for the management of crop production/ protection practices.

ISSN : 0974-9411 (Print), 2231-5209 (Online) All Rights Reserved (C) Applied and Natural Science Foundation www.jans.ansfoundation.org
One of the major causes of the low productivity is the damage done at various stages of the crop by different insect-pests. Maize crop is attacked by nearly 130 species of insect-pests in India (Atwal and Dhaliwal, 2002). Amongst these, the most serious pests are the maize stem borer, Chilo partellus Swinhoe, the key pest throughout the country during rainy season, pink stem borer, Sesamia inferens (Walker), serious in peninsular India in post rainy season and two species of shoot fly, Atherigona soccata and Atherigona nuquii, serious in spring maize in Northern India, which cause economic yield losses (Siddiqui and Marwaha, 1993). Recently, $S$. inferens has emerged as a new pest and is likely to pose serious threat to the successful cultivation of maize in the north-western plains of India under largely adopted rice-wheat/maize cropping system (Singh and Kular, 2015). Yield loss is mainly due to dead heart formation in maize crop (Siddiqui and Marwaha, 1993). In India, the losses due to pink stem borer on maize are reported to be varied from 25 to 80 per cent (Rao et al., 1983).

Since the pest plays havoc, economically important and the biology of $S$. inferens on maize has not yet been studied in the north-western plains of India, it was necessary to study biology of this pest in this region of India. Having regards to the fact that no systematic work on this aspect has been carried out, studies were conducted on biology of pink stem borer, $S$. inferens for developing efficient pest management 
strategies.

\section{MATERIALS AND METHODS}

Biological studies: This study on the biological parameters of pink stem borer, $S$. inferens was studied during October, 2015 to March, 2016 in laboratories of CCS Haryana Agricultural University, Regional Research Station, Karnal on maize genotypes, HQPM 1 (hybrid) and HKI 1128 (inbred). Scrutiny of available literature indicate that no information is available in the literature regarding the hibernation/diapause of $S$. inferens. Therefore, biology was carried out for two generations continuously to study the diapause of $S$. inferens during winter season. The culture was raised by collecting the full grown larvae from paddy fields and was reared on cut stem of rice. Adults obtained from this culture were reared on potted maize plants in ovipositional cages developed by Kumar et al., 2011. Adults were fed on 10 per cent honey solution. After release of the moths in ovipositional cages, potted plants were removed after 5-6 days and leaf sheaths containing egg masses were cut and kept for incubation in jars till the emergence of neonate larvae. Larvae were reared in cut stem portion of maize in tubes $(7 \times 2.5 \mathrm{~cm})$. In this way culture was maintained in laboratory for further biological studies.

The duration of developmental stages i.e. larval instars, pupal period were recorded by observing 100 individuals for each stage (20 individuals in 5 replications). For recording the adult longevity of $S$. inferens, adults were observed from the day emergence started. The duration of adults in each cage was recorded and longevity of each sex was calculated. For recording preoviposition, oviposition and post-oviposition period the newly emerged pairs of $S$. inferens were collected and confined in new insect rearing cages keeping 20 replications i.e. for adults from HQPM-1 and HKI 1128. Each cage was observed daily during oviposition period for recording the fecundity of females. The numbers of eggs laid by female inside the leaf sheath were examined. A pair of freshly emerged male and female moth was introduced on 10-15 days old potted plants. Plants were removed daily to check egg laying. Leaf sheath containing egg portion were cut and new potted plants was introduced daily till their death. The per cent hatchability, larval survival and adult emergence were recorded by observing 250 (50 per replicate in 5 replications) number of egg, larvae and pupa, each. The length and width of different stages were measured in the first generation, with the help of ocular and stage micrometer by observing 10 individuals of each stage viz. egg, first to sixth instar, pupa and adult (male and female) under the stereoscopic zoom binocular microscope.

Statistical analysis: The data collected during present studies were statistically analyzed. Data on various biological parameters of $S$. inferens were subjected to statistical analysis by calculating mean value and ' $t$ ' test. Standard deviation was also calculated for all biological parameters.

\section{RESULTS AND DISCUSSION}

Observations on biology of $S$. inferens on maize hybrid (HQPM 1) and inbred (HKI 1128) are presented in Tables 1-3 and 8-10. The morphometrics of different stages of the $S$. inferens are provided in Table 4-7. The images of life cycle of the $S$. inferens are provided in Plate 1.

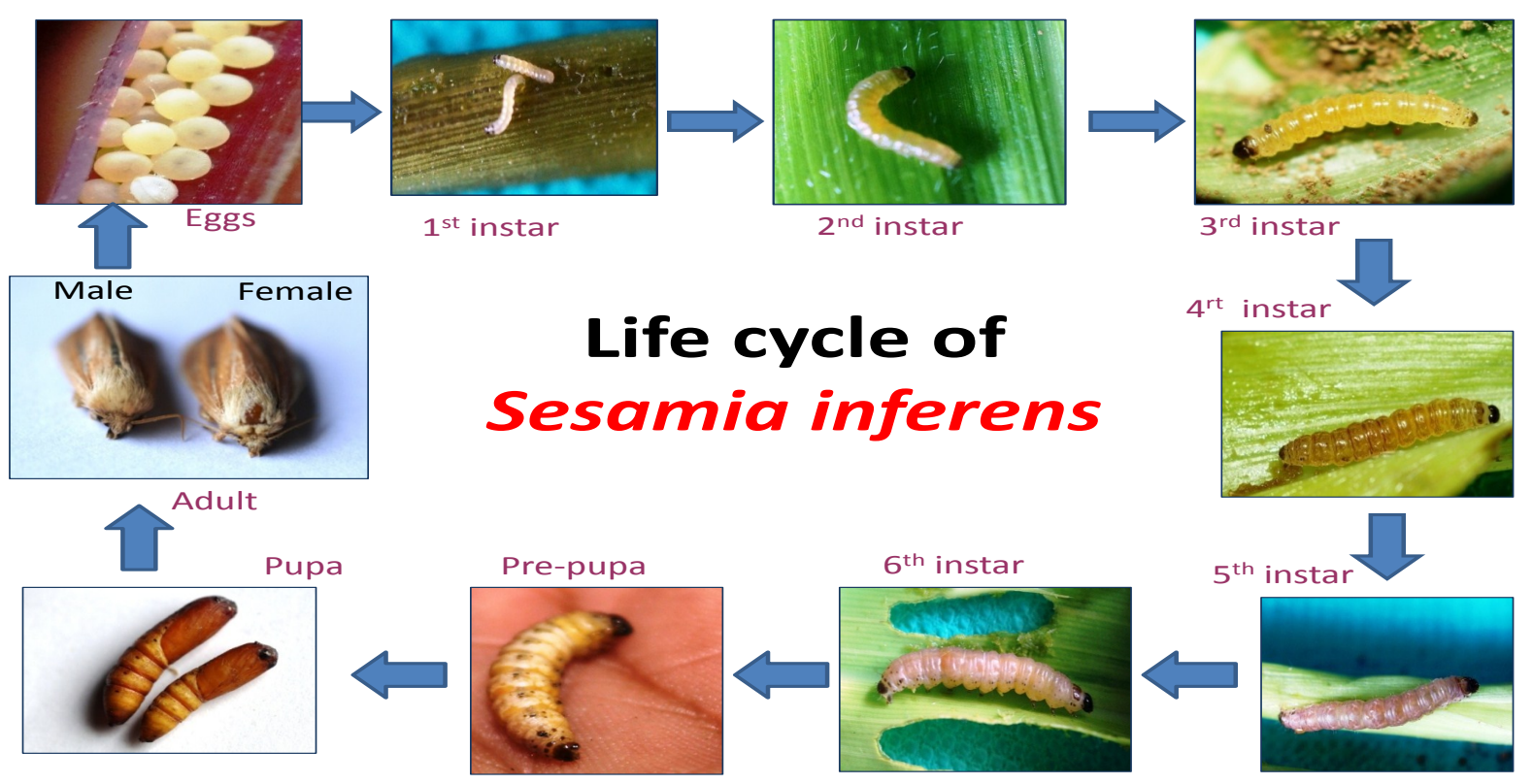

Plate 1. Different life stage of S. inferens on maize. 
Hemant Sharma et al. / J. Appl. \& Nat. Sci. 9 (4): 1994 - 2003 (2017)

Table 1. Duration of different immature stages of $S$. inferens on maize genotypes (HQPM-1 and HKI 1128) during first generation.

\begin{tabular}{|c|c|c|c|c|c|c|}
\hline \multirow{3}{*}{ Insect stage } & \multirow{3}{*}{$\begin{array}{l}\text { Number } \\
\text { observed }\end{array}$} & \multicolumn{4}{|c|}{ Maize genotypes } & \multirow{3}{*}{ 't' value } \\
\hline & & \multicolumn{2}{|c|}{ HQPM 1 (hybrid) } & \multicolumn{2}{|c|}{ HKI 1128 (inbred) } & \\
\hline & & Mean \pm SD & Range & Mean \pm SD & Range & \\
\hline \multicolumn{7}{|l|}{ Larvae } \\
\hline $1^{\text {st }}$ larval instar (days) & 100 & $3.18 \pm 0.52$ & $2-4$ & $3.36 \pm 0.48$ & $3-4$ & $2.52 *$ \\
\hline $2^{\text {nd }}$ larval instar (days) & 100 & $3.57 \pm 0.85$ & $3-5$ & $3.91 \pm 0.69$ & $3-6$ & $3.51 * *$ \\
\hline $3^{\text {rd }}$ larval instar (days) & 100 & $4.35 \pm 0.86$ & $3-6$ & $4.71 \pm 0.78$ & $4-6$ & $2.99 * *$ \\
\hline $4^{\text {th }}$ larval instar (days) & 100 & $4.99 \pm 1.04$ & $3-7$ & $5.39 \pm 0.99$ & $4-7$ & $2.84 * *$ \\
\hline $5^{\text {th }}$ larval instar (days) & 100 & $5.45 \pm 1.15$ & $4-7$ & $5.82 \pm 1.25$ & $4-8$ & $2.16^{*}$ \\
\hline $6^{\text {th }}$ larval instar (days) & 100 & $6.14 \pm 1.23$ & 4-8 & $6.53 \pm 1.20$ & $5-9$ & $2.56^{*}$ \\
\hline Total larval period (days) & 100 & $28.31 \pm 4.85$ & $21-37$ & $30.42 \pm 5.12$ & $24-39$ & $2.89^{* *}$ \\
\hline Pre-pupal Period (days) & 100 & $2.69 \pm 0.46$ & $2-3$ & $3.21 \pm 0.40$ & $3-4$ & $2.51 *$ \\
\hline \multicolumn{7}{|l|}{ Pupal Period (days) } \\
\hline Male & 100 & $10.95 \pm 1.38$ & $10-14$ & $11.22 \pm 1.81$ & $11-15$ & $2.69^{* *}$ \\
\hline Female & 100 & $15.59 \pm 0.84$ & $13-17$ & $15.81 \pm 1.07$ & $14-18$ & $2.86^{* *}$ \\
\hline Incubation period (days) & 100 & $12.21 \pm 0.69$ & $10-14$ & $13.54 \pm 0.85$ & $11-15$ & $4.73 * *$ \\
\hline \multicolumn{7}{|c|}{$*$ Significant at $\mathrm{p}=0.05, * *$ Significant at $\mathrm{p}=0.01$} \\
\hline Insect Stage & & \multicolumn{2}{|l|}{ Temperature (range) } & \multicolumn{3}{|c|}{ Relative humidity (range) } \\
\hline Larval Peroid & & \multicolumn{2}{|l|}{$23.1-28.8^{\circ} \mathrm{C}$} & \multicolumn{3}{|c|}{$53-76 \%$} \\
\hline Pre- Pupal\&Pupal Period & & \multicolumn{2}{|l|}{$21.1-23.4^{\circ} \mathrm{C}$} & \multicolumn{3}{|c|}{$54-68 \%$} \\
\hline Incubation Period & & \multicolumn{2}{|l|}{$16.4-20.9^{\circ} \mathrm{C}$} & \multicolumn{3}{|c|}{$57-71 \%$} \\
\hline
\end{tabular}

Table 2. Egg hatchability, larval survival, adult emergence and sex ratio of $S$. inferens on maize genotypes (HQPM-1 and HKI 1128) during first generation.

\begin{tabular}{lcccc}
\hline \multirow{2}{*}{ Parameter } & \multirow{2}{*}{$\begin{array}{c}\text { Number } \\
\text { observed }\end{array}$} & HQPM 1 (hybrid) & HKI 1128 (inbred) & \multirow{2}{*}{ 't' value } \\
\cline { 3 - 4 } & 250 eggs & 76.6 & 69.4 & $3.73^{* *}$ \\
Egg hatchability (\%) & 250 larvae & 58.4 & 50.6 & $4.73^{* *}$ \\
larval survival (\%) & 250 pupae & 93.4 & 87.6 & $6.88^{* *}$ \\
Adult Emergence (\%) & 250 adults & $1: 1.17$ & $1: 1.06$ & 1.68 \\
Sex Ratio (F:M) & &
\end{tabular}

*Significant at $\mathrm{p}=0.05, * *$ Significant at $\mathrm{p}=0.01$

Table 3. Duration of different adult stages of $S$. inferens on maize genotypes (HQPM-1 and HKI 1128) during first generation.

\begin{tabular}{|c|c|c|c|c|c|c|}
\hline \multirow{3}{*}{ Insect stage } & \multirow{3}{*}{$\begin{array}{l}\text { Number } \\
\text { Observed }\end{array}$} & \multicolumn{4}{|c|}{ Maize genotypes } & \multirow{3}{*}{ 't' value } \\
\hline & & \multicolumn{2}{|c|}{ HQPM 1 (hybrid) } & \multicolumn{2}{|c|}{ HKI 1128 (inbred) } & \\
\hline & & Mean \pm SD & Range & Mean \pm SD & Range & \\
\hline \multicolumn{7}{|l|}{ Adult } \\
\hline Pre oviposition period (days) & 20 & $1.2 \pm 0.31$ & $1-2$ & $1.9 \pm 0.56$ & $1-3$ & $3.89 * *$ \\
\hline Oviposition period (days) & 20 & $4.8 \pm 0.42$ & $4-5$ & $4.3 \pm 0.67$ & $3-5$ & $3.29 * *$ \\
\hline Post oviposition period (days) & 20 & $1.7 \pm 0.48$ & $1-2$ & $1.1 \pm 0.31$ & $1-2$ & 1.99 \\
\hline Copulation period(minutes) & 20 & $286 \pm 34$ & $230-343$ & $248 \pm 31$ & $210-293$ & $2.62 *$ \\
\hline \multicolumn{7}{|l|}{ Adult longevity } \\
\hline Female & 20 & $7.3 \pm 0.48$ & $7-8$ & $6.6 \pm 0.51$ & $6-7$ & $3.79 * *$ \\
\hline Male & 20 & $6.2 \pm 0.42$ & $6-7$ & $5.7 \pm 0.48$ & $5-7$ & $3.56 * *$ \\
\hline \multicolumn{7}{|l|}{ Total life cycle } \\
\hline Female & 20 & $66.3 \pm 3.12$ & $63-72$ & $69.3 \pm 3.59$ & $65-74$ & $3.75^{* *}$ \\
\hline Male & 20 & $51.1 \pm 4.17$ & $45-58$ & $54.5 \pm 4.24$ & $49-62$ & $3.45 * *$ \\
\hline Fecundity / female & 20 & $222.5 \pm 60$ & $106-277$ & $38.5 \pm 72$ & $9-205$ & $2.82 *$ \\
\hline
\end{tabular}

*Significant at $\mathrm{p}=0.05, * *$ Significant at $\mathrm{p}=0.01$

\section{Biology of $S$. inferens}

Egg: The freshly laid eggs of $S$. inferens were hemispherical and having fine ridges in 2-4 longitudinal rows. The eggs became brownish or light pinkish from creamy white when they were near to hatch and finally turned ash grey before hatching. The diameter of egg varied from 0.72 to $0.88 \mathrm{~mm}$ and 0.70 to $0.84 \mathrm{~mm}$ with an average diameter $0.78 \pm 0.053$ and $0.75 \pm 0.041 \mathrm{~mm}$ on HQPM 1 and HKI 1128, respectively (Table 4). ). According to Joshi (2005) eggs of S. inferens measured 0.6 to $0.7 \mathrm{~mm}$ in diameter on rice. Reddy (2001) and Joshi (2005) also reported hemispherical eggs of $S$. inferens with regular ridges measured 0.6 to $0.7 \mathrm{~mm}$ in diameter on maize and rice, respectively. However, Tyagi and Sharma (1989) reported a diameter of 0.95 $\mathrm{mm}$ for $S$. inferens which gives partial support to the 
Hemant Sharma et al. / J. Appl. \& Nat. Sci. 9 (4): 1994 - 2003 (2017)

Table 4. Morphometrics (length) of various life stages of S. inferens reared on maize hybrid (HQPM-1) and maize inbred (HKI 1128).

\begin{tabular}{|c|c|c|c|c|c|c|}
\hline \multirow{3}{*}{ Insect Stage $\mathbf{e}^{* * *}$} & \multirow{3}{*}{$\begin{array}{l}\text { Number } \\
\text { observed }\end{array}$} & \multicolumn{4}{|c|}{ Maize genotypes } & \multirow{3}{*}{ 't $t$ " value } \\
\hline & & \multicolumn{2}{|c|}{ HQPM 1 (hybrid) } & \multicolumn{2}{|c|}{ HKI 1128 (inbred) } & \\
\hline & & Mean \pm SD & Range & Mean \pm SD & Range & \\
\hline \multicolumn{7}{|l|}{ HQPM-1 } \\
\hline Egg (diameter) & 10 & $0.78 \pm 0.053$ & $0.72-0.88$ & $0.75 \pm 0.041$ & $0.70-0.84$ & 0.83 \\
\hline \multicolumn{7}{|l|}{ Larvae } \\
\hline $1^{\text {st }}$ instar larvae & 10 & $1.86 \pm 0.21$ & $1.58-2.06$ & $1.79 \pm 0.18$ & $1.52-1.96$ & 1.37 \\
\hline $2^{\text {nd }}$ instar larvae & 10 & $3.91 \pm 0.60$ & $3.36-4.81$ & $3.71 \pm 0.49$ & $3.24-4.71$ & 1.65 \\
\hline $3^{\text {rd }}$ instar larvae & 10 & $8.02 \pm 1.49$ & $6.03-10.04$ & $7.58 \pm 1.31$ & $5.37-9.03$ & $2.17 *$ \\
\hline $4^{\text {th }}$ instar larvae & 10 & $13.80 \pm 0.86$ & $12.35-14.83$ & $12.98 \pm 0.92$ & $11.51-14.28$ & $5.51 * *$ \\
\hline $5^{\text {th }}$ instar larvae & 10 & $22.19 \pm 1.58$ & $20.32-24.17$ & $18.01 \pm 1.80$ & $15.76-21.39$ & $7.28 * *$ \\
\hline $6^{\text {th }}$ instar larvae & 10 & $31.25 \pm 2.06$ & 27.84-34.92 & $25.52 \pm 1.38$ & $23.52-28.16$ & $5.89 * *$ \\
\hline Pre-pupa & 10 & $18.35 \pm 0.72$ & $17.75-19.27$ & $16.63 \pm 0.56$ & $15.57-17.27$ & $3.01 *$ \\
\hline \multicolumn{7}{|l|}{ Pupa } \\
\hline Male & 10 & $14.05 \pm 0.47$ & $12.95-14.71$ & $13.28 \pm 0.66$ & $12.47-13.89$ & $4.05 * *$ \\
\hline Female & 10 & $15.65 \pm 0.51$ & $14.98-16.31$ & $14.05 \pm 0.23$ & $13.61-14.31$ & $4.35 * *$ \\
\hline \multicolumn{7}{|l|}{ Adult } \\
\hline Male & 10 & $13.89 \pm 0.66$ & $12.95-14.78$ & $13.74 \pm 0.67$ & $12.60-14.58$ & $3.51 *$ \\
\hline Female & 10 & $14.74 \pm 0.90$ & $13.34-15.93$ & $14.37 \pm 0.80$ & $13.04-15.45$ & $3.76^{*}$ \\
\hline
\end{tabular}

*Significant at $\mathrm{p}=0.05, * *$ Significant at $\mathrm{p}=0.01 * * *$ Measurements in $\mathrm{mm}$

Table 5. Morphometrics (width) of various life stages of $S$. inferens reared on maize hybrid (HQPM-1) and maize inbred (HKI 1128).

\begin{tabular}{|c|c|c|c|c|c|c|}
\hline \multirow{3}{*}{ Insect Stage $* * *$} & \multirow{3}{*}{$\begin{array}{l}\text { Number } \\
\text { observed }\end{array}$} & \multicolumn{4}{|c|}{ Maize genotypes } & \multirow{3}{*}{ ' $t$ ' test } \\
\hline & & \multicolumn{2}{|c|}{ HQPM 1 (hybrid) } & \multicolumn{2}{|c|}{ HKI 1128 (inbred) } & \\
\hline & & Mean \pm SD & Mean \pm SD & Mean \pm SD & Range & \\
\hline \multicolumn{7}{|l|}{ HQPM-1 } \\
\hline \multicolumn{7}{|l|}{ Larvae } \\
\hline $1^{\text {st }}$ instar larvae & 10 & $0.41 \pm 0.04$ & $0.36-0.47$ & $0.39 \pm 0.04$ & $0.33-0.45$ & 1.24 \\
\hline $2^{\text {nd }}$ instar larvae & 10 & $0.66 \pm 0.07$ & $0.59-0.78$ & $0.62 \pm 0.06$ & $0.53-0.74$ & 1.51 \\
\hline $3^{\text {rd }}$ instar larvae & 10 & $0.94 \pm 0.13$ & $0.81-1.17$ & $0.89 \pm 0.08$ & $0.79-1.07$ & 1.86 \\
\hline $4^{\text {th }}$ instar larvae & 10 & $1.54 \pm 0.24$ & $1.25-1.99$ & $1.44 \pm 0.16$ & $1.27-1.71$ & $2.96^{*}$ \\
\hline $5^{\text {th }}$ instar larvae & 10 & $2.83 \pm 0.18$ & $2.55-3.07$ & $2.53 \pm 0.17$ & $2.25-3.81$ & $3.98 * *$ \\
\hline $6^{\text {th }}$ instar larvae & 10 & $3.85 \pm 0.22$ & $3.51-4.21$ & $3.29 \pm 0.38$ & $2.87-3.81$ & $3.90 * *$ \\
\hline Pre-pupa & 10 & $3.64 \pm 0.24$ & $3.16-3.97$ & $3.25 \pm 0.21$ & $3.15-3.52$ & $5.38 * *$ \\
\hline \multicolumn{7}{|l|}{ Pupa } \\
\hline Male & 10 & $3.36 \pm 0.23$ & $3.08-3.77$ & $2.87 \pm 0.17$ & $2.57-3.05$ & $4.47 * *$ \\
\hline Female & 10 & $3.82 \pm 0.43$ & $3.21-4.35$ & $3.19 \pm 0.13$ & $2.96-3.37$ & $4.56^{* *}$ \\
\hline \multicolumn{7}{|l|}{ Adult } \\
\hline Male & 10 & $25.71 \pm 0.68$ & $24.45-26.19$ & $25.36 \pm 0.57$ & $24.03-25.98$ & $2.27 *$ \\
\hline Female & 10 & $27.63 \pm 1.25$ & $25.75-29.13$ & $27.17 \pm 0.98$ & $25.41-28.43$ & $2.54 *$ \\
\hline
\end{tabular}

*Significant at $\mathrm{p}=0.05, * *$ Significant at $\mathrm{p}=0.01 * * *$ Measurements in $\mathrm{mm}$

present studies. Variation in diameter of eggs in present studies and that of above mentioned workers may be due to host plant and environmental factors.

Incubation period and hatchability: The incubation period of $S$. inferens varied from 10-14 days (average 12.21 days) on HQPM 1 and 11-15 days (average 13.54 days) on HKI 1128 in the first generation (October-December) and in the second generation (December- March), the eggs hatched in 7-10 days (average 8.35 days)on HQPM 1 and 8-11 days (average 9.71 days) on HKI 1128, respectively (Tables 1and 8). The findings of Easwaramoorthy et al. (1991) and Aggarwal et al. (2004) who reported that the incubation period varied from 5-8 days and 6-11 days for
$S$. inferens during October- November which give partial support to present findings. The findings of Joshi (2005) and Nagarjuna et al. (2015) who reported incubation period of $S$. inferens for 5-7 days and 5-6 days, respectively, give partial support to the present investigations where incubation period ranged from 7-15 days. The variations in findings of present studies and that of earlier workers may be due to variation in laboratory temperature, relative humidity and host plant.

The hatchability of $S$. inferens was 76.6 and 69.4 per cent on HQPM 1 and HKI 1128 in the first generation and for the second generation, the hatchability was 67.8 and 59.2 per cent on HQPM 1 and HKI 1128, respectively (Tables 2 and 9). The present results con- 
Hemant Sharma et al. / J. Appl. \& Nat. Sci. 9 (4): 1994 - 2003 (2017)

Table 6. Head capsule diameter of larvae and pupal weight of $S$. inferens on the plants of maize inbred HQPM-1 and HKI 1128.

\begin{tabular}{|c|c|c|c|c|c|c|c|}
\hline \multirow{3}{*}{$\begin{array}{l}\text { Sr. } \\
\text { No. }\end{array}$} & \multirow{3}{*}{ Insect stage } & \multirow{3}{*}{$\begin{array}{l}\text { Number } \\
\text { observed }\end{array}$} & \multicolumn{4}{|c|}{ Maize genotypes } & \multirow{3}{*}{ 't' test $* * *$} \\
\hline & & & \multicolumn{2}{|c|}{ HQPM-1 (hybrid) } & \multicolumn{2}{|c|}{ HKI 1128 (inbred) } & \\
\hline & & & Mean \pm SD & Range & Mean \pm SD & Range & \\
\hline & Larvae* & & & & & & \\
\hline 1. & $1^{\text {st }}$ instar larvae & 10 & $0.33 \pm 0.015$ & $0.32-0.36$ & $0.31 \pm 0.016$ & $0.30-0.34$ & 1.16 \\
\hline 2. & $2^{\text {nd }}$ instar larvae & 10 & $0.42 \pm 0.029$ & $0.38-0.46$ & $0.39 \pm 0.027$ & $0.36-0.42$ & 1.09 \\
\hline 3. & $3^{\text {rd }}$ instar larvae & 10 & $0.73 \pm 0.023$ & $0.70-0.76$ & $0.70 \pm 0.015$ & $0.68-0.72$ & \\
\hline 4. & $4^{\text {th }}$ instar larvae & 10 & $1.19 \pm 0.019$ & $1.18-1.22$ & $1.18 \pm 0.018$ & $1.16-1.20$ & 1.13 \\
\hline 5. & $5^{\text {th }}$ instar larvae & 10 & $1.62 \pm 0.025$ & $1.58-1.66$ & $1.59 \pm 0.023$ & $1.56-1.62$ & 1.24 \\
\hline \multirow[t]{2}{*}{6.} & $6^{\text {th }}$ instar larvae & 10 & $2.03 \pm 0.413$ & $1.96-2.06$ & $1.99 \pm 0.035$ & $1.94-2.04$ & 1.16 \\
\hline & Pupae** & & & & & & \\
\hline 7. & Male & 10 & $0.996 \pm 0.009$ & $0.89-0.114$ & $0.865 \pm 0.012$ & $0.67-0.108$ & $2.24 * * *$ \\
\hline 8. & Female & 10 & $0.1411 \pm 0.021$ & $0.122-0.196$ & $0.1124 \pm 0.009$ & $0.97-0.123$ & $2.43 * * *$ \\
\hline
\end{tabular}

*Diameter of Head Capsule in mm, **Weight of Pupae in grams, ***Significant at $\mathrm{p}=0.01$

Table 7. Morphometrics of different identifying characters of $S$. inferens pupae and adults.

\begin{tabular}{|c|c|c|c|c|c|c|c|}
\hline \multirow{3}{*}{$\begin{array}{l}\text { Sr. } \\
\text { No. }\end{array}$} & \multirow{3}{*}{ Insect stage* } & \multirow{3}{*}{$\begin{array}{l}\text { Number } \\
\text { observed }\end{array}$} & \multicolumn{4}{|c|}{\begin{tabular}{|c|} 
Maize genotypes \\
\end{tabular}} & \multirow{3}{*}{ ' $t$ ' test $* *$} \\
\hline & & & \multicolumn{2}{|c|}{ HQPM-1 (hybrid) } & \multicolumn{2}{|c|}{ HKI 1128 (inbred) } & \\
\hline & & & Mean \pm SD & Range & Mean \pm SD & Range & \\
\hline \multirow[t]{3}{*}{1.} & Antennae (Adult) & & & & & & \\
\hline & Male & 10 & $4.84 \pm 0.215$ & $4.64-5.18$ & $4.76 \pm 0.295$ & $4.36-5.24$ & 1.21 \\
\hline & Female & 10 & $5.14 \pm 0.249$ & 4.74-5.42 & $5.02 \pm 0.307$ & $4.38-5.22$ & 1.14 \\
\hline \multirow[t]{3}{*}{2.} & Compound eyes (Pupae) & & & & & & \\
\hline & Male & 10 & $2.82 \pm 0.227$ & $2.48-3.22$ & $2.75 \pm 0.192$ & $2.46-3.14$ & 1.56 \\
\hline & Female & 10 & $3.14 \pm 0.359$ & $2.72-3.58$ & $2.91 \pm 0.227$ & $2.58-3.42$ & 1.13 \\
\hline \multirow[t]{3}{*}{3.} & Slit distance (Pupae) & & & & & & \\
\hline & Male & 10 & $0.75 \pm 0.013$ & $0.73-0.77$ & $0.73 \pm 0.022$ & $0.68-0.76$ & 1.11 \\
\hline & Female & 10 & $1.83 \pm 0.063$ & $1.76-1.92$ & $1.71 \pm 0.035$ & $1.66-1.78$ & 1.46 \\
\hline
\end{tabular}

*Measurements in $\mathrm{mm} * * \mathrm{NS}$

Table 8. Duration of different immature stages of $S$. inferens on maize genotypes (HQPM-1 and HKI 1128) during second generation.

\begin{tabular}{|c|c|c|c|c|c|c|}
\hline \multirow{3}{*}{ Insect stage } & \multirow{3}{*}{$\begin{array}{l}\text { Number } \\
\text { observed }\end{array}$} & \multicolumn{4}{|c|}{ Maize genotypes } & \multirow{3}{*}{ 't' value } \\
\hline & & \multicolumn{2}{|c|}{ HQPM 1 (hybrid) } & \multicolumn{2}{|c|}{ HKI 1128 (inbred) } & \\
\hline & & Mean \pm SD & Range & Mean \pm SD & Range & \\
\hline \multicolumn{7}{|l|}{ Larvae } \\
\hline $1^{\text {st }}$ larval instar (days) & 100 & $6.21 \pm 1.14$ & $5-7$ & $6.35 \pm 1.05$ & $5-8$ & $2.57 * *$ \\
\hline $2^{\text {nd }}$ larval instar (days) & 100 & $6.68 \pm 1.71$ & $5-8$ & $6.93 \pm 1.96$ & $6-8$ & $2.65 * *$ \\
\hline $3^{\text {rd }}$ larval instar (days) & 100 & $6.92 \pm 1.83$ & $6-9$ & $7.37 \pm 1.88$ & $7-9$ & $2.87 * *$ \\
\hline $4^{\text {th }}$ larval instar (days) & 100 & $7.16 \pm 1.56$ & $7-9$ & $7.83 \pm 1.75$ & $7-10$ & $2.45^{* *}$ \\
\hline $5^{\text {th }}$ larval instar (days) & 100 & $7.53 \pm 1.78$ & $7-10$ & $7.95 \pm 1.85$ & $7-11$ & $2.98^{* *}$ \\
\hline $6^{\text {th }}$ larval instar (days) & 100 & $7.78 \pm 2.03$ & $7-11$ & $8.09 \pm 1.91$ & $8-12$ & $2.53 * *$ \\
\hline $7^{\text {th }}$ larval instar (days) & 100 & $8.23 \pm 1.96$ & $8-11$ & $8.56 \pm 2.05$ & $8-12$ & $2.44 * *$ \\
\hline $8^{\text {th }}$ larval instar (days) & 100 & $8.78 \pm 2.15$ & $8-12$ & $9.15 \pm 2.25$ & $9-13$ & $2.35^{* *}$ \\
\hline Total larval period (days) & 100 & $61.29 \pm 4.28$ & $52-68$ & $64.43 \pm 5.39$ & $55-71$ & $2.78^{* *}$ \\
\hline Pre-pupal period (days) & 100 & $2.84 \pm 0.55$ & $2-4$ & $3.57 \pm 0.58$ & $3-4$ & $2.68^{*}$ \\
\hline \multicolumn{7}{|l|}{ Pupal period (days) } \\
\hline Male & 100 & $12.29 \pm 1.14$ & $10-15$ & $12.53 \pm 1.79$ & $11-15$ & $2.96^{* *}$ \\
\hline Female & 100 & $16.86 \pm 1.75$ & $15-18$ & $17.42 \pm 1.52$ & $15-19$ & $3.15^{* *}$ \\
\hline Incubation period(days) & 100 & $8.35 \pm 0.35$ & $7-10$ & $9.71 \pm 0.56$ & $8-11$ & $5.13 * *$ \\
\hline \multicolumn{7}{|c|}{ *Significant at $\mathrm{p}=0.05, * *$ Significant at $\mathrm{p}=0.01$} \\
\hline \multicolumn{2}{|l|}{ Parameter (Insect Stage) } & \multicolumn{2}{|c|}{ Temperature (range) } & \multicolumn{3}{|c|}{ Relative Humidity (range) } \\
\hline Larval peroid & & \multicolumn{2}{|c|}{$12.3-17.8^{\circ} \mathrm{C}$} & \multicolumn{3}{|c|}{$64-77 \%$} \\
\hline Pre- pupal\&pupal period & & \multicolumn{2}{|c|}{$17.3-20.5^{\circ} \mathrm{C}$} & \multicolumn{3}{|c|}{$51-73 \%$} \\
\hline Incubation period & & \multicolumn{2}{|c|}{$19.4-22.6^{\circ} \mathrm{C}$} & \multicolumn{3}{|c|}{$57-75 \%$} \\
\hline
\end{tabular}

firm to the findings of Tyagi and Sharma (1989) who reported 58.66 to 73.99 per cent hatchability. However, Aggarwal et al. (2004) and Joshi (2005) who re- ported hatchability ranging from 75.45-97.05 per cent for $S$. inferens which doesn t support to the present findings. Difference in hatchability might be due to 
Table 9. Egg hatchability, larval survival, adult emergence and sex ratio of $S$. inferens on maize genotypes (HQPM-1 and HKI 1128) during second generation.

\begin{tabular}{lcccc}
\hline \multirow{2}{*}{ Parameter } & \multirow{2}{*}{$\begin{array}{c}\text { Number } \\
\text { observed }\end{array}$} & \multicolumn{2}{c}{ Maize genotypes } & 't' value \\
\cline { 3 - 4 } & 250 eggs & 67.8 & HKI 1128 (inbred) & \\
\hline Egg hatchability (\%) & 250 larvae & 49.6 & 59.2 & $4.16^{* *}$ \\
larval survival (\%) & 250 pupae & 82.6 & 43.8 & $4.65^{* *}$ \\
Adult Emergence (\%) & 250 adults & $1: 1.09$ & 76.2 & $7.53^{* *}$ \\
Sex Ratio (F:M) & 252.52 & 1.02 \\
\hline
\end{tabular}

*Significant at $\mathrm{p}=0.05, * *$ Significant at $\mathrm{p}=0.01$

Table 10. Duration of different adult stages of $S$. inferens on maize genotypes (HQPM-1 and HKI 1128) during second generation.

\begin{tabular}{|c|c|c|c|c|c|c|}
\hline \multirow{3}{*}{ Insect stage } & \multirow{3}{*}{$\begin{array}{l}\text { Number } \\
\text { observed }\end{array}$} & \multicolumn{4}{|c|}{ Maize genotypes } & \multirow{3}{*}{ 't $t$ ' value } \\
\hline & & \multicolumn{2}{|c|}{ HQPM-1 (hybrid) } & \multicolumn{2}{|c|}{ HKI1128 (inbred) } & \\
\hline & & Mean \pm SD & Range & Mean \pm SD & Range & \\
\hline \multicolumn{7}{|l|}{ Adult } \\
\hline Pre oviposition period (days) & 20 & $1.1 \pm 0.23$ & $1-2$ & $1.5 \pm 0.25$ & $1-2$ & $3.75 * *$ \\
\hline Oviposition period (days) & 20 & $4.2 \pm 0.66$ & $4-5$ & $3.9 \pm 0.36$ & $3-5$ & $3.45 * *$ \\
\hline Post oviposition period (days) & 20 & $1.2 \pm 0.57$ & $1-2$ & $1.1 \pm 0.39$ & $1-2$ & $2.35 *$ \\
\hline Copulation period (minutes) & 20 & $253 \pm 39$ & $217-306$ & $215 \pm 42$ & $196-265$ & $2.73 *$ \\
\hline \multicolumn{7}{|l|}{ Adult longevity (days) } \\
\hline Female & 20 & $6.9 \pm 0.62$ & $6-8$ & $6.2 \pm 0.58$ & $5-7$ & $3.52 * *$ \\
\hline Male & 20 & $6.1 \pm 0.51$ & $5-7$ & $5.4 \pm 0.65$ & $4-6$ & $3.47 * *$ \\
\hline \multicolumn{7}{|l|}{ Total life cycle (days) } \\
\hline Female & 20 & $101.5 \pm 4.87$ & $94-107$ & $105.4 \pm 5.12$ & $98-112$ & $3.69 * *$ \\
\hline Male & 20 & $91.4 \pm 5.48$ & $83-96$ & $97.6 \pm 5.23$ & $86-101$ & $3.25 * *$ \\
\hline Fecundity /female & 20 & $196 \pm 48$ & $94-236$ & $112 \pm 57$ & $3-178$ & $2.73 * *$ \\
\hline
\end{tabular}

*Significant at $\mathrm{p}=0.05, * *$ Significant at $\mathrm{p}=0.01$

variation in environmental conditions.

Larval period: The larval period of $S$. inferens lasted for 21-37 days (average 28.31 days) on HQPM 1 and 24-39 days (average 30. 42 days) on HKI 1128 in the first generation (October-December) and for the second generation (December- March), the larval period of $S$. inferens ranged from 55-71 days (average 64.43 days) on HQPM 1 and 52-68 days (average 61.29 days) on HKI 1128 (Table 1and 8). The present results are in agreement with findings of Easwaramoorthy et al. (1991) and Tyagi and Sharma (1989) who reported that the total larval period ranged from 22-60 days for $S$. inferens. The findings of Lu and Tan (1981), Reddy (2001) and Aggarwal et al. (2004) who reported larval period of $S$. inferens for 21.9 - 28.3 days, 26.10 days and 22.9 days to 23.73 days, respectively also give partial support to the present findings of first generation. Findings of Joshi (2005), Nagarjuna et al. (2015) and Singh and Kular (2015) who reported larval duration of 53-74 days, 23- 39 days, 68.52 days, respectively also give partial support to the present findings of second generation. The variation in findings of present studies and that of earlier workers may be due to the difference in host plants, genotype or due to meteorological variation at the time of experimentation.

Number and duration of larval instars: The larvae of $S$. inferens passed through six instars in the first generation (October-December) to become a pupa on maize and it passed through eight instars in the second generation (December-March). Larvae did not hiber- nate in second generation, however, total larval duration was prolonged and eight instars were observed at low temperature (minimum $5.2^{\circ} \mathrm{C}$ and maximum $26.3^{\circ}$ C). The mean duration of first to sixth instar larvae (Table 1) was $3.18,3.57,4.35,4.99,5.45$ and 6.14 on HQPM 1 and 3.36, 3.91, 4.71, 5.39, 5.82 and 6.53 on HKI 1128, respectively in first generation (OctoberDecember). However, in the second generation the larvae passed through eight instars and duration was $6.35,6.93,7.37,7.83,7.95,8.09,8.56$ and 9.15 on HQPM 1 and 6.21, 6.68, 6.92, 7.16, 7.53, 7.78, 8.23 and 8.78 on HKI 1128 , respectively (Table 8 ). The present findings on larval instars and their duration are in agreement with those of Aggarwal et al. (2004) who reported that larvae of $S$. inferens passed through six instars with a duration of 2.34, 3.09, 3.97, 4.18, 4.70 and 5.44 days (May-October) and Atwal and Chaudhary (1967) who reported that larvae passed through eight instars and a mean duration of eight larval instars was 4.05, 4.45, 4.54, 5.08, 5.87, 6.91, 8.41 and 9.75 days, respectively. However, Rothschild (1971) reported seven instars and mean duration of $S$. inferens was 3.0, 3.4, 3.9, 4.6, 5.3, 6.6 and 13.0 days, respectively. The findings of Joshi (2005), Singh and Kular (2015) who observed that the larvae of $S$. inferens passed through eight instars to become a pupa also support present findings. The variation in present larval instars and their duration in present findings and findings of earlier workers may be due to the difference in host plant or due to meteorological variation at 
the time of experimentation.

I, II, III, IV, V and VI instar larvae when reared on HQPM $1\left(^{\text {st }}\right.$ generation) measured as $1.86 \pm 0.21$, $3.91 \pm 0.60, \quad 8.02 \pm 1.49, \quad 13.80 \pm 0.86, \quad 22.19 \pm 1.58$ and $31.25 \pm 2.06 \mathrm{~mm}$ in length and $0.41 \pm 0.04$, $0.66 \pm 0.07, \quad 0.94 \pm 0.13, \quad 1.54 \pm 0.24, \quad 2.83 \pm 0.18$ and $3.85 \pm 0.22 \mathrm{~mm}$ in width, respectively (Table 4$)$. The lengths of I, II, III, IV, V \& VI instar larvae when reared on HKI 1128 were $1.79 \pm 0.18,3.71 \pm 0.49$, $7.58 \pm 1.31,12.98 \pm 0.92,18.01 \pm 1.80$ and $25.52 \pm 1.38$ $\mathrm{mm}$ in length, respectively. The corresponding figures for width on HKI 1128 were $0.39 \pm 0.04,0.62 \pm 0.06$, $0.89 \pm 0.08, \quad 1.44 \pm 0.16, \quad 2.53 \pm 0.17 \quad \& \quad 3.29 \pm 0.38 \mathrm{~mm}$ (Table 4). The present findings with regard to length and width of full grown $S$. inferens larvae are in line with the Tyagi and Sharma (1989), Reddy (2001) and Kumar et al. (2012) who reported a length and width of $30.42 \mathrm{~mm}$ and $4.18 \mathrm{~mm}, 25-30 \mathrm{~mm}$ and 3-4 mm, 35 $\mathrm{mm}$ and $3.0 \mathrm{~mm}$ on maize, respectively. However, Joshi (2005) reported a length of 1.5 to $2.0 \mathrm{~mm}$ for $1^{\text {st }}$ instar larvae and $22-24 \mathrm{~mm}$ for last instar larvae on rice. The variation in length might be due to different environmental conditions and host plant on which test insect was reared. Head capsule diameter of $1^{\text {st }}$ instar larvae measured as $0.33 \pm 0.015 \mathrm{~mm}$ (range 0.32-0.36 $\mathrm{mm}$ ) and $0.31 \pm 0.016 \mathrm{~mm}$ (range $0.30-0.34 \mathrm{~mm}$ ) on HQPM 1 and HKI 1128, respectively. Head capsule diameter of $1^{\text {st }}$ instar larvae measured as $0.33 \pm 0.015$ $\mathrm{mm}$ (range 0.32-0.36 $\mathrm{mm}$ ) and $0.31 \pm 0.016 \mathrm{~mm}$ (range $0.30-0.34 \mathrm{~mm}$ ) on HQPM 1 and HKI 1128, respectively. Head capsule diameter of $6^{\text {th }}$ instar larvae measured as $2.03 \pm 0.413 \mathrm{~mm}$ (range 1.96-2.06 $\mathrm{mm}$ ) and $1.99 \pm 0.035 \mathrm{~mm}$ (range 1.94-2.04 $\mathrm{mm}$ ) on HQPM 1 and HKI 1128, respectively (Table 7). No information is available in literature on the head capsule diameter of different larval instars of $S$. inferens.

Per cent larval survival: The larval survival of $S$. inferens was 58.4 per cent on HQPM 1 and 50.6 per cent on HKI 1128 in the first generation (OctoberDecember) and for the second generation (DecemberMarch), the larval survival of $S$. inferens was 49.6 per cent on HQPM 1 and 43.8 per cent on HKI 1128, respectively(Tables 2 and 9). The present findings are confirmatory with Tyagi and Sharma (1989) who reported that the larval survival (48 per cent) on maize. However, Shanower et al. (1993) reported 30 per cent larval survival of $S$. inferens on maize stems. However, Joshi (2005) reported that larval survival was 36.0 per cent on rice. The variation in larval survival might be due to different environmental conditions, maize genotypes (resistant/susceptible) and host plant on which test insect was reared.

Adult emergence: The adult emergence of $S$. inferens was 93.4 and 87.6 per cent on HQPM1 and HKI 1128 in the first generation (October-December) and for the second generation (December- march) adult emergence of pink stem borer was82.6 and 76.2 per cent on
HQPM 1 and HKI 1128, respectively(Tables 2 and 9). The present studies are in agreement with the findings of Qureshi et al. (1971) who reported that adult emergence of 50-80 per cent. Similar findings on the per cent moth emergence was observed by Easwaramoorty et al. (1991) (86.27 to 92.88 in different generations) and Joshi (2005) (94.05 per cent). However, Tyagi and Sharma (1989) reported maximum adult emergence on maize was 40.8 per cent; do not support results of present findings. Different resistant/ susceptible genotypes used as food by different workers might have attributed difference in adult emergence of present investigations.

Sex ratio: The sex ratio of pink stem borer was $1: 1.17$ (F: M) and 1:1.06 (F: M) on HQPM 1 and HKI 1128 in the first generation (October-December) and for the second generation (December- march), the sex ratio of pink stem borer was1:1.09 (F: M) and 1:1.02 (F: M) on HQPM 1 and HKI 1128, respectively (Tables 2 and 9). However, sex ratio on two genotypes did not differ significantly. The data indicated that males outnumbered females which derive support from the research findings of Zhou and Chen (1985) who observed sex ratio (female: male) of 1: 1.2. Joshi (2005) also reported a male to female ratio of 1: 0.92 for $S$. inferens which are in tune with the present findings. However, Aggarwal et al. (2004) who reported sex ratio of 1: 1.10 and 1: 1.03 for male to female during the month of October- December and May - September, respectively.

Pre-pupal and pupal period: The mean duration of pre-pupa lasted for 2-3 days (average 2.69 days) on HQPM 1 and 3-4 days (average 3.57 days) on HKI 1128 in the first generation (October-December) and for the second generation (December- March), the mean duration of pre-pupa lasted for 2-4 days (average 2.84 days) on HQPM 1 and 3-4 days (average 2.69 days) on HKI 1128, respectively (Tables 1 and 8 ). The duration of male and female pupae ranged from 10-14 days (average 10.95 days) and 13-17 days (average 15.59 days) on HQPM 1 and 10-15 days (average 11.22 days) and 14-18 days (average 15.81 days) on HKI 1128 in the first generation (October-December) and for the second generation (December- March), the mean duration of male and female pupae ranged from 10-15 days (average 12.29 days) and 11-15 days (average 16.86 days) on HQPM 1 and 10-15 (average 12.53 days) and 15-19 days (average 17.42 days) on HKI 1128, respectively (Tables 1 and 8). Joshi (2005) reported pre-pupal duration of 2.24 days for $S$. inferens which give partial support to the present findings. The present results on pupal duration are in agreement with findings of the Eawaramoorthy et al. (1991) and Rajendra (1976) who reported that the pupal period ranged from 9-12 days. The findings of Aggarwal et al. (2004) who reported pupal period of 7-9 days for male and 7-10 days for female with the pre-pupal peri- 
od of 1-2 days, respectively also give partial support to the present findings of first generation. However, Singh and Kular (2015) reported pupal duration of $36.05 \pm 0.36$ days in male while $37.78 \pm 0.17$ days in female, respectively. The variation in findings of Singh and Kular (2015) to that of present studies may be due to the difference in host plants and due to meteorological variation at the time of experimentation.

On average, pre-pupa measured $18.35 \pm 0.72 \mathrm{~mm}$ and $16.63 \pm 0.56 \mathrm{~mm}$ in length and $3.64 \pm 0.24 \mathrm{~mm}$ and $3.25 \pm 0.21 \mathrm{~mm}$ on HQPM 1 and HKI 1128, respectively (Table 4). The length and width of pre-pupae were statistically significant on HQPM 1 and HKI 1128 genotypes. No information is available on morphometric studies of pre-pupae of $S$. inferens in the literature. On average, male pupae was $14.05 \pm 0.47 \mathrm{~mm}$ and $13.28 \pm 0.66 \mathrm{~mm}$ in length and $3.36 \pm 0.23 \mathrm{~mm}$ and $2.87 \pm 0.17 \mathrm{~mm}$ on HQPM 1 and HKI 1128 , respectively (Table 4). The corresponding figures for female pupae were $15.65 \pm 0.51 \mathrm{~mm}$ and $14.05 \pm 0.23 \mathrm{~mm}$ in length and $3.82 \pm 0.43 \mathrm{~mm}$ and $3.19 \pm 0.13 \mathrm{~mm}$ on HQPM 1 and HKI 1128, respectively (Table 4). The length and width of male and female pupae were statistically significant on HQPM 1 and HKI 1128 genotypes. The present findings derives support from Tyagi and Sharma (1989) who reported female pupae measuring $18.7 \mathrm{~mm}$ in length and $4.9 \mathrm{~mm}$ in width and male pupae measuring $15.40 \mathrm{~mm}$ length and $3.8 \mathrm{~mm}$ width. Similarly, Reddy (2001) reported that female pupae of $S$. inferens had length of 17-20 mm and width of 4-5 $\mathrm{mm}$ while male pupae of $S$. inferens had length of 15$16 \mathrm{~mm}$ and width of $3.5-4 \mathrm{~mm}$ give support to present findings.

The weight of male and female pupa ranged from 0.67 - $0.108 \mathrm{~g}$ and $0.97-0.123 \mathrm{~g}$ with an average pupal weight of $0.865 \pm 0.012 \mathrm{~g}$ and $0.1124 \pm 0.009 \mathrm{~g}$ on HKI 1128 and on HQPM 1 the weight of male and female ranged from $0.89-0.114 \mathrm{~g}$ and $0.122-0.196 \mathrm{~g}$ with a average pupal weight of $0.996 \pm 0.009 \mathrm{~g}$ and $0.1411 \pm 0.021 \mathrm{~g}$, respectively (Table 6). The weight of male and female pupae were statistically significant on HQPM 1 and HKI 1128 genotypes. The present findings on the weight of $S$. inferens pupae are in agreement with the Reddy (2001) who reported a weight of $0.1338 \mathrm{~g}$ for female pupae and $0.1023 \mathrm{~g}$ for male pupae of $S$. inferens on maize. However, Joshi (2005) reported a weight of $0.797 \mathrm{~g}$ for male pupae and 0.968 $\mathrm{g}$ for female pupae of $S$. inferens on rice. The variation in weight of pupae might be due to different environmental conditions, host plant and genotype on which test insect was reared. The distance of compound eyes of the male and female pupae averaged $2.82 \pm 0.227$ $\mathrm{mm}$ and $3.14 \pm 0.359 \mathrm{~mm}$, respectively on HQPM 1 . However, compound eyes of male and female pupae on HKI 1128 averaged $2.75 \pm 0.192 \mathrm{~mm}$ and $2.91 \pm 0.227 \mathrm{~mm}$, respectively. Compound eyes of females have more distance than males. No information is available on distance of compound eyes of male and female pupae of $S$. inferens in the literature.

The slit distance of the male and female pupae varied from $0.73-0.77 \mathrm{~mm}$ and $1.76-1.92 \mathrm{~mm}$ with mean slit distance of $0.75 \pm 0.013 \mathrm{~mm}$ and $1.83 \pm 0.063 \mathrm{~mm}$, respectively on HQPM 1 (Table 7). However, slit distance of male and female pupae on HKI 1128 varied $0.68-0.76 \mathrm{~mm}$ and $1.66-1.78$ with a mean of $0.73 \pm 0.022 \mathrm{~mm}$ and $1.71 \pm 0.035 \mathrm{~mm}$, respectively (Table 6). The slit distance of female pupa has more distance than male pupa. This character could be easily seen by naked eyes and used as identifying character for male and female pupae of $S$. inferens. No systematic information is available in the literature on the slit distance of male and female pupae of $S$. inferens. However, Patel and Verma (1980) reported that female pupae have larger slit distance than male pupae give partial support to present findings.

Adult: The male moths obtained from HQPM 1 and HKI 1128 genotypes measured 13.89 \pm 0.66 (range $12.95-14.78$ ) and $14.74 \pm 0.90$ (range 13.34-15.93) in length and $25.71 \pm 0.68(24.45-26.19)$ and $25.36 \pm 0.57$ (24.03-25.98) in wing expense, while female moths measured 14.74 \pm 0.90 (range 13.34-15.93) and $14.37 \pm 0.80$ (range 13.04-15.45) in length and $27.63 \pm 1.25(25.75-29.13)$ and $27.17 \pm 0.98$ (25.4128.43), respectively (Table 4). The present findings derives support from Tyagi and Sharma (1989) who reported female moth measuring 25 to $29 \mathrm{~mm}$ in wing expanse and $12-15 \mathrm{~mm}$ in length and male moth measuring 23 to $26 \mathrm{~mm}$ wing expanse and 11 to $14 \mathrm{~mm}$ length, respectively. However, Reddy (2001) reported that adult of $S$. inferens had length of $15-18 \mathrm{~mm}$ with a wing expanse of 30-33 mm and male was smaller than female. The variation in length and width might be due to different environmental conditions and host plants, genotypes (susceptible/ resistant) on which test insect was reared.

The sexes can be distinguished by type of antennae of male and female moths. The antennae of the male and female adults varied from 4.64-5.18 $\mathrm{mm}$ and 4.74-5.42 $\mathrm{mm}$ with mean length of $4.84 \pm 0.215 \mathrm{~mm}$ and $5.14 \pm 0.249 \mathrm{~mm}$, respectively on HQPM 1 (Table 7). However, length of antennae of male and female adults on HKI 1128 varied $4.36-5.24 \mathrm{~mm}$ and $4.38-5.22 \mathrm{~mm}$ with a mean length of $4.76 \pm 0.295 \mathrm{~mm}$ and $5.02 \pm 0.307$ $\mathrm{mm}$, respectively (Table 7). Females have longer antennae than males but this character might not be used as identifying character of $S$. inferens (adults). The sexes of $S$. inferens could be distinguished by type of antennae. Studies in present investigations showed that males of $S$. inferens have pectinate antennae and females have filiform antennae. No information is available on the length of male and female antennae and type of antennae of $S$. inferens in the literature. However, Patel and Verma (1980) reported that females have larger antennae than males. 
Adult longevity: The longevity of male and female of S. inferens fed on HQPM 1 varied from 6-7 days and 7 -8 days, respectively (Table 3 ). However, the male and female of $S$. inferens fed on HKI 1128 survived for 5-7 days and 6-7 days, respectively in the first generation (October-December). In the second generation (December- march), the male and female of $S$. inferens fed on HQPM 1 survived for 5-7 days and 6-8 days on HKI 1128 survived for 4-6 days and 5-7 days, respectively (Table 10). The present results are in agreement with findings of the Lu and Tan (1981) and Aggarwal et al. (2004) who reported adult longevity of $S$. inferens up to 3 to 6 days. However, Joshi (2005) reported adult longevity of 8-13 days for males and 9-17 days for females of $S$. inferens. Nagarjuna et al. (2015) reported longevity 3 to 5 days for males and 5 to 7 days for females of $S$. inferens. Singh and Kular (2015) also reported adult longevity 5.31 days for male of $S$. inferens and 6.61 days for female of $S$. inferens also give partial support to the present findings. The variation in findings of present studies and that of earlier workers may be due to the difference in host plants or due to meteorological variation at the time of experimentation.

Fecundity: The number of eggs laid by female of $S$. inferens on HQPM 1 varied from $106-277$ eggs and it varied from 9-205 eggs on HKI 1128 during its oviposition period in the first generation (OctoberDecember) and for the second generation (Decembermarch), the number of eggs laid by female of $S$. inferens varied 94-236 eggs/female on HQPM 1 and it varied 3-178 eggs/female on HKI 1128, respectively (Tables $3 \& 10$ ). The present results are in accordance with findings of the Qureshi et al. (1971) and Zhou and Chen (1985) who observed the total no. of eggs laid by the females during their life span ranged from 8 -300. The findings of Tyagi and Sharma (1989) and Easwaramoorthy et al. (1991) who reported fecundity of 100 to 240 eggs and 54.33 eggs, respectively also give partial support to the present findings. The results of Reddy (2001) who reported that fecundity/female was 174.66 eggs in resistant genotype (Antigua Gr 1) and 204.99 eggs in susceptible genotype (Basi local) also give support to the present findings as fecundity/ female varied on HQPM-1 and HKI 1128 in the present studies. The variation in findings of present studies and that of earlier workers may be due to the difference in host plants, genotypes (susceptible/ resistant) or due to meteorological variation during the period of study.

Copulation period: The copulation period of $S$. inferens ranged 230-343 minutes with a mean of $286 \pm 34$ minutes and 210-293 minutes with a mean of $248 \pm 31$ minutes in HQPM1 and HKI 1128, respectively in the first generation (October-December) and for the second generation (December- march), the copulation period of $S$. inferens ranged 217-306 minutes with a mean of 253 \pm 39 minutes and 196-265 minutes with a mean of $215 \pm 42$ minutes in HQPM1 and HKI 1128, respectively (Tables 3 and 10). The present results are in accordance with findings of Nagarujuna et al. (2015) who reported that the mating period of $S$. inferens was 285 minutes. However, Nagayama et al. (2004) reported that the mean mating duration of $S$. inferens was $1.29 \pm 0.71 \mathrm{~h}$. The variation in findings of present studies may be due to the temperature, difference in host plants, genotypes or due to any other meteorological variation at the time of experimentation.

\section{Pre-oviposition, oviposition and post oviposition} period: The pre-oviposition period of $S$. inferens ranged from 1-2 days (average 1.2 days) on HQPM 1 and 1-3 days (average 1.9 days) on HKI 1128 in the first generation (October-December) and for the second generation (December- March) the preoviposition period of $S$. inferens ranged from 1-2 days (average 1.1 days) in HQPM 1 and 1-3 days (average 1.5 days) in HKI 1128, respectively (Tables 3and 10).The oviposition period of $S$. inferens ranged from 4-5 days (average 4.8 days) on HQPM 1 and 3-5 days (average 4.3 days) on HKI 1128 in the first generation (October-December) and for the second generation (December- March), the oviposition period ranged from 4-5 days(average 4.2 days) on HQPM 1 and 3-5 days (average 3.9 days) on HKI 1128, respectively (Tables 3and 10). The post oviposition of $S$. inferens ranged from 4-5 days (average 1.7 days) on HQPM 1 and 3-5 days (average 1.1 days) on HKI 1128 in the first generation (October-December) and for the second generation (December- March), the post oviposition of $S$. inferens was 4-5 days (average 1.2 days) on HQPM 1 and 3-5 days (average 1.1 days) on HKI 1128 , respectively (Tables 3and 10). Aggarwal et al. (2004) reported that pre-oviposition, oviposition period and post-oviposition period ranged from 1.2-1.8, 1.2-2.4 and 2.2-3.2 days, respectively give partial support to the present findings. However, Joshi (2005) reported that average pre-oviposition,oviposition and post-oviposition periods were 1.4 days, 7.6 days and 1.4 days. The variation in findings of present studies may be due to the temperature, difference in host plants, genotypes (resistant/ susceptible) or due to any other meteorological variation at the time of investigations.

Total life cycle: The total life span of females varied from 63-72 days (average 66.3 days) and 65-74 days (average 69.3 days) while those of males ranged from 45-58 days (average 51.1 days) and 49-62 days (54.5 days) on HQPM 1 and HKI 1128, respectively in the first generation (October-December) and for the second generation (December- March), the total life span of females varied from 94-107 days (average 101.5 \pm 4.87 days) and 98-112 days (average 105.4 \pm 5.12 days) while those of males ranged from 83 96 days (average 91.4 \pm 5.48 days) and 86-101days 
(97.6 \pm 5.23 days) on HQPM 1 and HKI 1128, respectively(Tables 3 and 10). Nagarujuna et al. (2015) reported that the total life cycle of $S$. inferens varied between 35-57 days on maize during summer season. However, Singh and Kular (2015) reported during winter season, total life cycle took 116.9 and 119.9 days in males and females, respectively, which are more or less in accordance with the present investigations. The findings of Aggarwal et al. (2004) who reported total life span varied from 52-78 days in males and 53-82 days in females give partial support to findings of present investigations in second generation. The variation in findings of present studies and that of earlier workers may be due to the difference in host plants, genotypes or due to meteorological variation at the time of investigations.

\section{Conclusion}

The biology of an insect pest is a condition precedent to find out its management strategies. The biology of $S$. inferens on maize was not studied in north western part of the country. Having regards to the fact that no systematic work on this aspect has been carried out, studies were conducted on biology of this pest which will be helpful for developing efficient pest management strategies against $S$. inferens.

\section{REFERENCES}

Aggarwal, R., Singh, J. and Shukla, K.K. (2004). Biology of pink stem borer, Sesamia inferens (Walker) on rice crop. Indian Journal of Ecoogy, 31(1): 66-67

Anonymous. (2014). Statistical Abstract of Haryana. Published by Department of Economic and Statistical Analysis, Haryana, pp. 239, $242 \& 252$

Atwal, A. S. and Dhaliwal, G. S. (2002). Agricultural Pests of South Asia and their Management. Kalyani Publishers, New Delhi, pp.189-192

Atwal, A. S. and Chaudhary, J. P. (1967). Studies on the insect pests of rice. Annual Report, Department of Zoology-Entomology, Punjab Agricultural University, Ludhiana, pp. 55-77

Easwaramoorthy, S., David, H. and Shanmugasundaram, M. (1991). Laboratory technique for mass multiplication of pink stem borer, Sesamia inferens (Walker). Entomon, 16: $223-227$

Joshi, G. (2005). Population dynamics of paddy borers and biology of pink borer, Sesamia inferens (Walker). M. Sc Thesis submitted to CCS Haryana Agricultural University, Hisar

Kumar, P., Sekhar, J. C., Kaur, J., Bana, J. K. and Suby. S. B. (2012). Screening techniques for maize germplasm. Directorate of Maize research, New Delhi, pp. 1-31

Kumar, P., Suby, S. B., Sekhar, J. C. and Kumar R. S.
(2011). A Collapsible insect nearing cage. Patent Application No. 0923/DEL/2011

Lu, Z.X. and Tan, L.S. (1981). Preliminary observations on the bionomics of Sesamia inferens (Walker). Insect Knowledge, 18(4): 151-154

Nagarjuna, B., Manjunath, M. and Latha, M. (2015). Biology of maize stem borer, Sesamia inferens (Walker) Noctuidae: Lepidoptera. Journal of Eco-friendly Agriculture, 10(1): 90-91

Nagayama, A., Arakaki, N., Kishita, M. and Yamada, Y. (2004). Emergence and mating behavior of the pink stem borer, Sesamia inferens (Walker). Aplied Entomology and Zoology, 39: 625-629

Patel, R. K. and Verma, R. (1980). Sex dimorphism in pink stem borer, Sesamiainferens (Walker) (Lepidoptera: Noctuidae). Science \&Culture, 46(5): 195-196

Qureshi, Z. A., Anwar, M. A., Chatha, N. U. and Aruf, M. D. (1971). Rearing, biology and sterilization of pink stem borer. In: Symp. Rice Insect. Proc. Symp. Trop. Agri. Res. Tropical Agriculture Researchers, 19-24 July, 1971. Trop. Agriculture Research. Serious No. 5, Tokyo, Japan, pp. 75-79

Rajendra, A. (1976). Studies on Sesamia inferens (Walker), the shoot-borer pest of the Sugarcane in Sri Lanka. Journal of Natural Science Foundation of Sri Lanka., 4 (2): 99-108

Rao, S., Venugopal, C. N. and Razvi, S.A.( 1983). Parasitism, a key factor in checking rice pest population. Entomon, 8: $97-100$

Reddy, M. L. K. (2001). Bio-ecology and management of Sesamia inferens (Walker) on maize. Ph.D Thesis Acharya N G Ranga Agricultural University, Rajendranagar, Hydrabad, India

Shanower, G. T., Schulthess, F. and Bosque-perez, N. 1993. The effect of larval diet on the growth and development of Sesamia calamitis Hampson (Lepidoptera: Noctuidae) and Eldana saccharina Walker (Lepidoptera: Pyralidae). Insect Science and its Applcation, 14(5):681685

Siddiqui, K. H. and Marwaha, K. K. (1993). The vistas of Maize Entomology in India.Kalyani Publishers, New Delhi.p 184

Singh, B. and Kular, J. S. (2015). Notes on the Bionomics of the Pink Stem Borer Sesamia inferens(Walker) (Lepidoptera: Noctuidae): An Upcoming Pest of Wheat in India. Published online, DOI: http:// dx.doi.org/10.1556/038.50.2015.2.9

Rothschild, G. H. L. 1971. The biology and ecology of rice stem borers in Sarawak (Malaysian Borneo). Journal of Applied Ecology, 8: 287-322

Tyagi, M. P. and Sharma, V. K. (1989). Biology of pink stem borer, Sesamia inferens (Walker) on different host plants. Bulletin of Entomology, 27(2): 191

Zhou, C. B. and Chen, A. F. (1985). Observations on the bionomics and hibernations of Sesamia inferens (Walker) in the northern part of Hainan Island. Insect Knowledge, 22(5): 199-201 